\title{
Methodology for Analysis and Design of Discrete Time Current Controllers for Three-Phase PWM Converters
}

\author{
Christoph H. van der Broeck, Sebastian A. Richter, Jochen von Bloh, and Rik W. De Doncker
}

\begin{abstract}
In this work, a methodology for the analysis and design of robust, high bandwidth current controllers for three phase converters is presented. The overall goal is to demonstrate how the proposed model based control structure and the design methodology lead to an optimized digital current controller that exhibits fast and smooth dynamics as well as an excellent disturbance rejection ability. First, accurate discrete time models are derived and used to review classical current control from the perspective of the synchronous and stationary reference frame. Then, implementation options for the synchronous frame proportional integral (SFPI) regulator and the proportional resonant (PR) regulator are discussed and systematically compared in the stationary frame leading to the formulation of a general controller framework based on space vector resonators. It embodies multiple complex resonators and can represent the SFPI regulator, the PR regulator and beyond that any higher order regulator structure. For this framework, a step by step design procedure based on the complex root locus is proposed that allows an insightful optimization of its feedback gains. Finally, the performance of the presented control design techniques is evaluated experimentally.
\end{abstract}

Index Terms - Control design, current control, digital control, PWM converter, root-locus method.

\section{INTRODUCTION}

$\mathrm{T}$ HE aim of this work is to provide an insightful framework for the design and efficient implementation of discrete time current control structures for grid-tied three-phase PWM converters. The synchronous-frame PI (SFPI) regulator [1] and the proportional-resonant (PR) regulator [2] are the most common regulators used for three-phase PWM converters, e.g. in active rectifiers or inverters for distributed power generation [3]. In a consistent control structure with proper state feedback decoupling and command feedforward [25], [29] they provide high bandwidth current control with infinite stiffness and zero steady state error at grid frequency.

For PWM converters operating at low switching frequencies accurate discrete time modeling is necessary for high bandwidth control design [24]. Basic discrete time modeling and control techniques for SFPI regulators and PR regulators have been

Manuscript received April 17, 2018.

C. H. van der Broeck and R. W. De Doncker are with Institute for Power Electronics and Electrical Drives(ISEA), RWTH Aachen University, Aachen, Germany (e-mail: post@isea.rwth-aachen.de).

S. A. Richter and J. von Bloh are with AixControl GmbH, Aachen, Germany (e-mail: info@aixcontrol.de).

Digital Object Identifier 10.24295/CPSSTPEA.2018.00025 explored in [4], [5]. They offer high accuracy, since they allow analyzing and designing the dynamics of a computer controlled system in its natural domain. For example, the latched characteristics of the voltage pattern generated by a PWM modulated converter and the update delay can be modeled accurately. Based on these models widely explored design tools like state space control [6] or the root locus method [7] can be used to obtain optimized feedback gains. This is not possible working with continuous time models where typically the open loop transfer function is used to design the controller. The optimization of the phase margin and the crossover frequency [8] only guarantee the stability of the closed loop system, but both cannot be directly related to certain closed loop characteristics e.g. damping, bandwidth or stiffness properties.

With the stronger integration of power electronics in the distribution grid, the harmonic content of the grid voltage increases in many grid areas [26], [27]. Without any further measures, neither SFPI nor PR regulators can reject the effect of voltage components of higher order and the emission of higher order current harmonics is the consequence. Thus, for the accurate control of the converter current at fundamental frequency and the rejection of higher order disturbance voltages multiple SFPI/PR regulators are used in [9], [10], [26] and [32] or alternatively repetitive control structures are applied as in [11], [27], [28] and [12].

Especially at a small carrier to fundamental frequency ratio, it is important to design the current control structure strategically in such a way that the fundamental current is smoothly controlled with high bandwidth and higher order voltage harmonics and disturbances are effectively rejected [25], [27]. In the literature most research approaches the control design in the continuous time domain [3], [13], [14], [31], [32]. However, a control design in the discrete time domain allows more realistic insight in the converter operation if the control bandwidth reaches close to the sampling frequency of the system, as illustrated in [5],[29] and [30]. For this reason, this paper aims to present a consistent discrete time modeling and design methodology to optimize the control structure and feedback gains for current controllers in grid tied applications.

This work, which is based on [22], firstly derives an accurate discrete time model for grid tied converters. Based on this model suitable decoupling structures and a trajectory generator are implemented together with a SFPI regulator using classical design methods and assuming ideal decoupling. To compare the SFPI and the PR regulator, the SFPI regulator is first formulated in the stationary frame [13]. It is demonstrated how the 


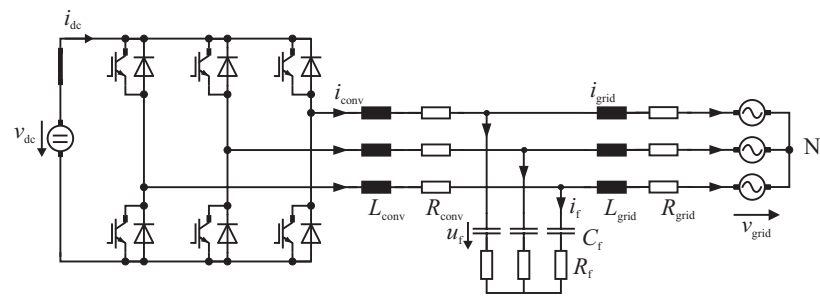

Fig. 1. Three-phase PWM converter with LCL filter.

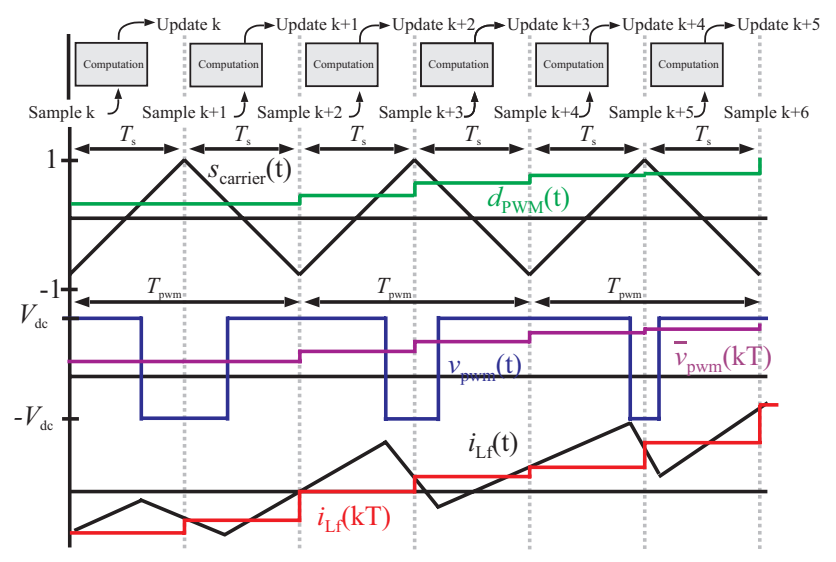

Fig. 2. Pulse width modulation of one converter half-bridge.

root locus method can be generalized for complex single-input single-output (SISO) systems in order to make it an effective design tool for any three phase control design. With this tool, the PR and SFPI regulator are optimized and compared. Finally, it is demonstrated how multiple space vector resonators can be tied together in a regulator structure called "Resonant Space Vector (RSV) regulator". This structure allows an efficient implementation and a consistent design of higher order current regulators. The discussed implementation and design concepts are validated in simulation and experiments.

\section{Model Development}

In this section, a discrete time model of a PWM converter with LCL filter (Fig. 1) is developed. In a first modeling step, the converter circuitry is replaced by ideal voltage sources, which represent the average voltage applied to the filter (Fig. 3). The control bandwidth of most converters is significantly below the resonance frequency of the LCL filter. Thus, in the frequency range of the control loops the capacitor $C_{\mathrm{f}}$ behaves like an open circuit and can be omitted in the control model (Fig. 4). This model only consists of an inductance $L_{\mathrm{f}}=L_{\text {conv }}+L_{\text {grid }}$ and a parasitic resistance $R_{\mathrm{f}}=R_{\text {conv }}+R_{\text {grid }}$, which form a so called L-filter model The neutral point of the converter system is isolated. Thus, the three phase currents and voltages can be transformed to two orthogonal space vector components [3] via the $\alpha \beta$-transform resulting in the simplified equivalent circuit of the three phase converter shown in Fig. 5. The $\alpha \beta$-space vectors can be formulated as complex quantities to reduce the system complexity. Thereby, the converter, which is oritignally a scalar multiple-input multiple-output (MIMO) system is reduced to a complex

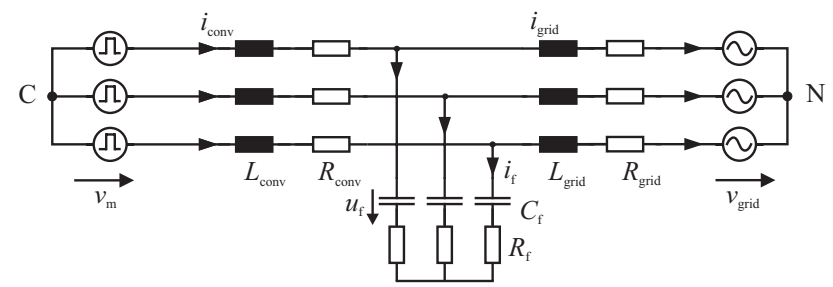

Fig. 3. Simplified model of the converter with LCL filter.

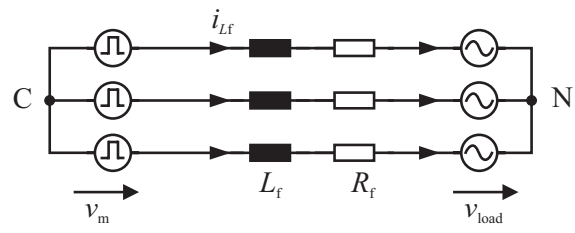

Fig. 4. Control model.

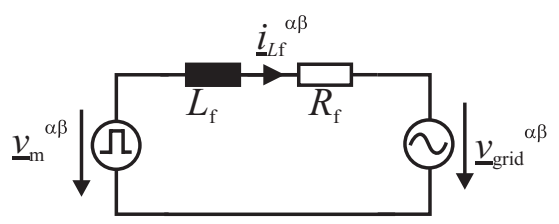

Fig. 5. Model in the $\alpha \beta$ frame.

single-input single-output (SISO) system like it is presented in [14] and [15].

Most control analysis and synthesis tools in the Laplace- and z-domain can be adopted for these complex systems as it is illustrated in [16] and [17]. Based on the differential equation of the simplified system

$$
L_{\mathrm{f}} \frac{\mathrm{d}}{\mathrm{d} t} \underline{i}_{L \mathrm{f}}{ }^{\alpha \beta}=\underline{v}_{\mathrm{m}}^{\alpha \beta}-R_{\mathrm{f}} \underline{i}_{L \mathrm{f}}{ }^{\alpha \beta}-\underline{v}_{\text {grid }}^{\alpha \beta},
$$

which describes the dynamics of the current $\underline{i}_{\mathrm{Lf}}^{\alpha \beta}$ in the inductance $L_{\mathrm{f}}$ and the resistance $R_{\mathrm{f}}$ as a function of the modulated converter voltage $\underline{v}_{\mathrm{m}}{ }^{\alpha \beta}$ and the grid voltage $\underline{v}_{\text {grid }}{ }^{\alpha \beta}$, the transfer function $\underline{G}_{\text {filter }}(s)^{\alpha \beta}(2)$ of the L-filter can be determined as a function of the time constant $\tau_{\mathrm{f}}=L_{\mathrm{f}} / R_{\mathrm{f}}$.

$$
\underline{G}_{\text {filter }}(s)^{\alpha \beta}=\frac{\underline{I}_{L \mathrm{f}}(s)^{\alpha \beta}}{\underline{V}_{\mathrm{m}}(s)^{\alpha \beta}-\underline{V}_{\text {grid }}(s)^{\alpha \beta}}=\frac{1}{R_{\mathrm{f}}} \frac{1}{s \tau_{\mathrm{f}^{+}}}
$$

For the voltage modulation, a classical asymmetrical regular sampled PWM [18] is used to realize a space vector modulation [20], which allows applying an arbitrary three-phase average voltage to the filter. The voltage modulation process for one half bridge of the converter is depicted in Fig. 2. At the top and bottom of the carrier signal $s_{\text {carrier }}$ the duty cycle $d_{\text {PWM }}$ is updated and the converter current $i_{\mathrm{Lf}}$ is measured and sampled. This synchronous sampling allows capturing the average current. The computer control system can be operated at a sampling frequency of twice the PWM frequency. However, as the duty cycle is only updated twice per PWM interval, there is a constant update delay of $T_{\text {update }}=T_{\mathrm{s}}$. 


\section{A. Discrete Time Converter Model}

The discrete time model of a PWM converter connected to the utility grid is developed based on the state block diagram of the plant depicted in Fig. 6. It takes into account the low bandwidth filter dynamics of the LCL filter (2), the update delay of the controller $\underline{G}_{\text {update }}(z)=z^{-1}$, and the modulator dynamics. The low-pass characteristic of the inductive load ensures that only the average voltage contributes to the average rate of change of the current. Therefore, the applied voltage pulses are approximated as a latch with a zero-order hold model in the stationary frame [5]. The zero-order hold model is applied according to (3) following [23].

$$
\underline{G}_{\mathrm{conv}}(z)^{\alpha \beta}=\frac{\underline{I}_{L \mathrm{f}}(z)^{\alpha \beta}}{\underline{V}_{\mathrm{m}}(z)^{\alpha \beta}}=\left(1-z^{-1}\right) \mathrm{Z}\left\{\frac{\underline{G}_{\text {filter }}(s)^{\alpha \beta}}{s}\right\} .
$$

For a negligible small resistance, the plant time constant $\tau_{\mathrm{f}}=L_{\mathrm{f}} /$ $R_{\mathrm{f}}$ approaches inifity and the discrete time transfer function can be simplified via (4) using L'Hopital's rule. The same results can also be obtained by directly discretizing the transfer function of an inductance and can be found in [24].

$$
\begin{aligned}
& \underline{G}_{\text {conv }}(z)^{\alpha \beta}=\frac{1}{R_{\mathrm{f}}} \frac{\left(1-\mathrm{e}^{-T_{\mathrm{S}} / \tau \mathrm{f}}\right) z^{-1}}{1-\mathrm{e}^{-T_{\mathrm{S}} / \tau_{\mathrm{f}}} z^{-1}} \stackrel{R \mathrm{f} \rightarrow 0}{=} \frac{1}{L_{\mathrm{f}}} \frac{z^{-1}}{1-z^{-1}} \lim _{\tau \mathrm{f} \rightarrow \infty}\left\{\left(1-\mathrm{e}^{-T_{\mathrm{S}} / \tau \mathrm{f}}\right) \tau_{\mathrm{f}}\right\} \\
& \underline{G}_{\text {conv }}(z)^{\alpha \beta}=\frac{1}{L_{\mathrm{f}}} \frac{T_{\mathrm{s}} z^{-1}}{1-z^{-1}}
\end{aligned}
$$

The discrete time model of the plant is completed by adding the update delay $\underline{G}_{\text {update }}(z)$, which takes into account the delay between the sampling of the currents and voltages and the update of the PWM duty cycle.

$$
\underline{G}_{\mathrm{p}}(z)^{\alpha \beta}=\frac{\underline{I}_{L \mathrm{f}}(z)^{\alpha \beta}}{\underline{V}_{\mathrm{m}}{ }^{*}(z)^{\alpha \beta}}=\frac{1}{L_{\mathrm{f}}} \frac{T_{\mathrm{s}} z^{-1}}{1-z^{-1}} z^{-1} .
$$

For most common control designs, the plant is transformed into the synchronous reference frame, which rotates with the grid frequency $\omega_{\mathrm{e}}$, to design a PI regulator for dc-quantities. This model transformation can be done by back shifting of the coordinate transformation (6) and applying the z-transformation on the backshifted difference (7) resulting in (8).

$$
\begin{gathered}
\underline{x}^{\alpha \beta}(k)=\underline{x}^{\mathrm{dq}}(k) \mathrm{e}^{j \omega_{\mathrm{e}} k T_{\mathrm{s}}} \\
\underline{x}^{\alpha \beta}(k-1)=\underline{x}^{\mathrm{dq}}(k-1) \mathrm{e}^{j \omega_{\mathrm{e}} k T_{\mathrm{s}}} \mathrm{e}^{-\mathrm{j} \omega_{\mathrm{e}} T_{\mathrm{s}}} . \\
\underline{X}^{\alpha \beta}(z) z^{-1}=\underline{X}^{\mathrm{dq}}(z) z^{-1} \mathrm{e}^{-\mathrm{j} \omega_{\mathrm{e}} T_{\mathrm{s}}}
\end{gathered}
$$

Consequently, a discrete time transfer function can be transferred from the stationary to the synchronous reference frame, which rotates at an angular frequency of $\omega_{e}$, by replacing all $z^{-1}$ with $\mathrm{z}^{-1} \mathrm{e}^{-\mathrm{j} \omega_{\mathrm{e}} T_{\mathrm{s}}}$. The transfer function of the system in the synchronous frame (9), which is derived following this procedure, exhibits complex coefficients due to the crosscoupling between d- and q-component which results from the reference frame transformation.

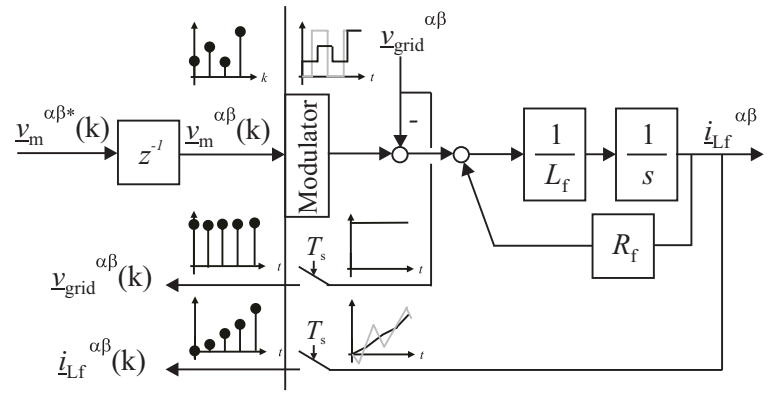

Fig. 6. State block diagram of the converter connected to the grid.

$$
\underline{G}_{\text {conv }}(z)^{\mathrm{dq}}=\frac{1}{L_{\mathrm{f}}} \frac{T_{\mathrm{s}} \mathrm{e}^{-\mathrm{j} \omega_{\mathrm{e}} T_{\mathrm{s}}} z^{-1}}{1-\mathrm{e}^{-\mathrm{j} \omega_{\mathrm{e}} T_{\mathrm{s}}} z^{-1}} z^{-1} \mathrm{e}^{-\mathrm{j} \omega_{\mathrm{e}} T_{\mathrm{s}}}
$$

\section{B. Discrete Time Grid Voltage Model}

Another part of the converter model that needs to be derived is the discrete time system response to the grid voltage. It describes the impact of the sampled grid voltage $\underline{v}_{\text {grid }}(k)$ on the sampled current $\underline{i}_{\mathrm{Lf}}(k)$. The discrete time grid voltage model cannot be developed from the stationary frame inductor model (5), because this does not accurately model the sinusoidal characteristics of the grid voltage. Instead the grid voltage applied to the L-filter

$$
\underline{G}_{\text {grid }}(s)^{\mathrm{dq}}=\frac{\underline{I}_{L \mathrm{f}}(s)^{\mathrm{dq}}}{\underline{V}_{\text {grid }}(s)^{\mathrm{dq}}} \stackrel{R \mathrm{f} \rightarrow 0}{=} \frac{1}{s L_{\mathrm{f}}+j \omega_{\mathrm{e}} L_{\mathrm{f}}}
$$

can be latched in the dq-frame (11). This corresponds to a perfect construction of a sinusoidal voltage in the stationary frame.

$$
\begin{gathered}
\underline{G}_{\text {grid }}(z)^{\mathrm{dq}}=\frac{\underline{I}_{L \mathrm{f}}(z)^{\mathrm{dq}}}{\underline{V}_{\text {grid }}(z)^{\mathrm{dq}}}=\left(1-z^{-1}\right) \mathrm{Z}\left\{\frac{\underline{G}_{\text {grid }}(s)^{\mathrm{dq}}}{s}\right\} \\
\underline{G}_{\text {grid }}(z)^{\mathrm{dq}}=\operatorname{sinc}\left(\frac{\omega_{\mathrm{e}} T_{\mathrm{s}}}{2}\right) \frac{T_{\mathrm{s}} \mathrm{e}^{-\mathrm{j} \omega_{\mathrm{e}} T_{\mathrm{s}} / 2} z^{-1}}{1-\mathrm{e}^{-\mathrm{j} \omega_{\mathrm{e}} T_{\mathrm{s}}} z^{-1}}
\end{gathered}
$$

The resulting transfer function (12) can be simplified, as the sinc-function is approximately 1 for the cases of interest

$$
\underline{G}_{\text {grid }}(z)^{\mathrm{dq}}=\frac{\underline{I}_{L \mathrm{f}}(z)^{\mathrm{dq}}}{\underline{V}_{\text {grid }}(z)^{\mathrm{dq}}} \approx \frac{1}{L_{\mathrm{f}}} \frac{T_{\mathrm{s}} \mathrm{e}^{-\mathrm{j} \omega_{\mathrm{e}} T_{\mathrm{s}} / 2} z^{-1}}{1-\mathrm{e}^{-\mathrm{j} \omega_{\mathrm{e}} T_{\mathrm{s}}} z^{-1}} .
$$

Comparing the converter and grid voltage model (9) and (13), it is important to realize that the sampled grid voltage and the converter voltage exhibit a different rotation in steady state.

The knowledge about the discrete time dynamics of the system can be assembled to a discrete time converter model as depicted in the grey box in Fig. 7.

\section{Current Control ImPlementation In the DQ-Frame}

The developed model is the basis for the current control implementation, which is discussed in the following section. It is discussed in many publications, e.g. in [3] and [8], that it is important to make the dynamics of the $\mathrm{d}$ - and q-current unaffected 


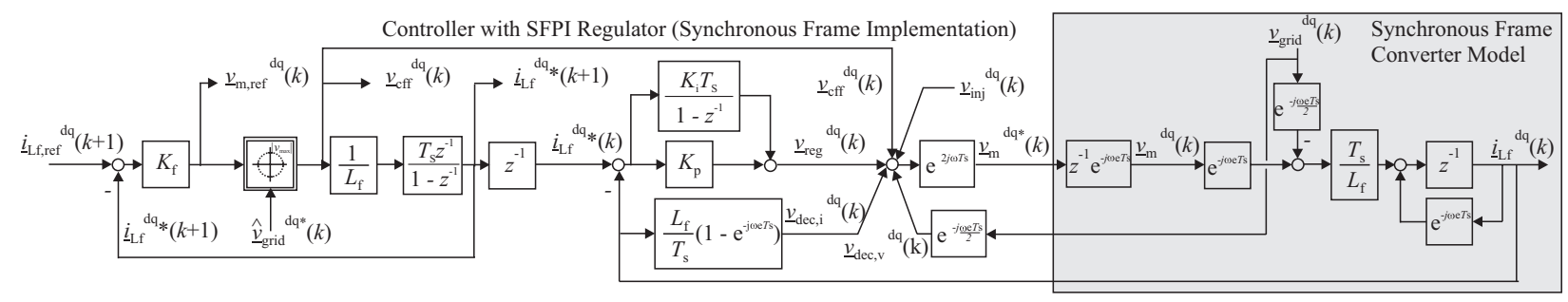

Fig. 7. State block diagram of the discrete time current control structure with command filter in the synchronous frame.

from each other. The elimination of crosscoupling allows to reduce oscillations and increases the bandwidth and stiffness of the control system. However, this decoupling is typically done based on continuous time models, and does not take into account the discrete nature of the control algorithm. To overcome this limitation in the following section accurate discrete time decoupling measures are discussed, their performance is analyzed with a standard control design and the command tracking is improved with a command trajectory filter and a feedforward path.

\section{A. State Feedback Decoupling Structure}

The required decoupling structure can be developed based on the system model. If no additional predictor or observer structure is applied, due to the update delay introduced in (5), the decoupling can only be done quasi stationary, which was discussed in [21]. The forward decoupling path

$$
\underline{v}_{\mathrm{m}}{ }^{\mathrm{d} \mathrm{dq}}(k)=\mathrm{e}^{2 \mathrm{j} \omega \mathrm{e} T \mathrm{~s}} \underline{v}_{\mathrm{m}, \mathrm{dec}}{ }^{\mathrm{dq}}(k)
$$

compensates for the phase shift of the delays, whereas the feedback $\underline{v}_{\text {dec,iLf }}^{\text {dq }}$ decoupling compensates the current crosscoupling, while a minor error causes by the update delay remains.

$$
\underline{v}_{\mathrm{dec}, \mathrm{i}}{ }^{\mathrm{dq}}(k)=L_{\mathrm{f}} / T_{\mathrm{s}}\left(1-\mathrm{e}^{-\mathrm{j} \omega \mathrm{e} T \mathrm{~s}}\right) \underline{i}_{\mathrm{Lf}}^{\mathrm{dq}}(k)
$$

The grid voltage is decoupled in steady state with phase compensation according to (16)

$$
\underline{v}_{\text {dec, }, \mathrm{vq}}^{\mathrm{dq}}(k)=\mathrm{e}^{-\mathrm{j} 0.5 \omega \mathrm{e} T \mathrm{~s}} \underline{v}_{\text {grid }}^{\mathrm{dq}}(k),
$$

taking into account the combined grid voltage converter model. The entire state feedback decoupling structure is depicted in the state block diagram of the controlled plant in Fig. 7 together with the SFPI regulator.

\section{B. Classical SFPI Regulator Design and Performance Anal- ysis}

After the decoupling, the control design of $K_{\mathrm{p}}$ and $K_{\mathrm{i}}$ can be pursued in the dq-frame e.g. based on the phase margin [8], the root-locus method [5] or the technical or symmetrical optimum (SO) [19]. As the focus of this section is set on the control structure, the feedback gains are designed with the symmetrical optimum, which is a very common control design method. For this design the converter dynamics are assumed to be ideally

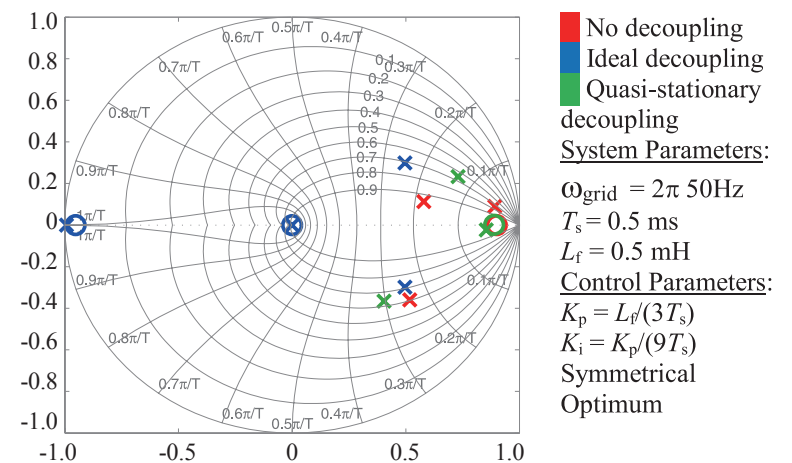

Fig. 8. SFPI control design with the symmetrical optimum $(a=2)$.

decoupled and approximated by a $1^{\text {st }}$ order lag element with the time constant $T_{\mathrm{d}}=T_{\text {update }}+T_{\text {latch }}=1.5 T_{\mathrm{s}}$, which results from the update delay and the characteristics of the modulator that is moded as a latch with $T_{\text {latch }}=0.5 T_{\mathrm{s}}$. The open loop transfer function

$$
\underline{G}_{0}(s)=\underline{G}_{\mathrm{c}}(s) \underline{G}_{\mathrm{p}}(s)=\frac{1}{s T_{\mathrm{d}}+1} \frac{1}{s L_{\mathrm{f}}}\left(K_{\mathrm{p}}+\frac{K_{\mathrm{i}}}{s}\right)
$$

for $R_{\mathrm{f}}=0$ is used for the control design. The symmetrical optimum design for the continuous time model leads to the following SFPI regulator gains:

$$
K_{\mathrm{p}}=\frac{1}{a} \frac{L_{\mathrm{f}}}{T_{\mathrm{d}}} ; K_{\mathrm{i}}=K_{\mathrm{p}} \frac{1}{a^{2}} \frac{1}{T_{\mathrm{d}}}
$$

The gains obtained from this quasi continuous control design are used as feedback gains for the discrete time control structure depicted in Fig. 7. Typically, these gains are computed for $a=2$ as this optimizes the disturbance rejection ability and the robustness of the simplified closed loop system. In Fig. 8 the closed loop poles and zeros for this particular control design are shown for 3 scenarios: The plant without any decoupling measures between $\mathrm{d}$ - and q-axis, the ideally decoupled plant (18), which does not exhibit cross coupling between $\mathrm{d}$ - and q-quantities, and the quasi-stationary decoupled plant as it is depicted in Fig. 7.

For the ideally decoupled plant, which is purely a reference scenario for the control design and not a realizable scenario, complex conjugated poles with a damping of $\xi=1 / \sqrt{2}$ are realized. This placement is desirable, as the so called optimal damping of $\xi=1 / \sqrt{2}$ provides the strongest disturbance rejection possible without overshoot, which can be observed in Fig. 9. If only a PI regulator in the synchronous reference frame is used and 


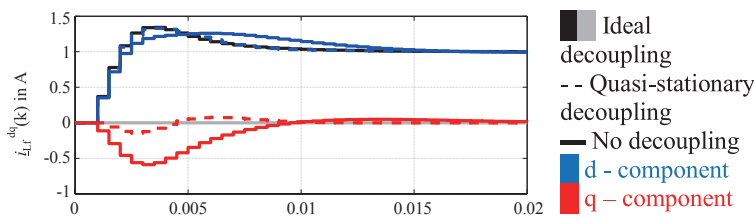

(a)

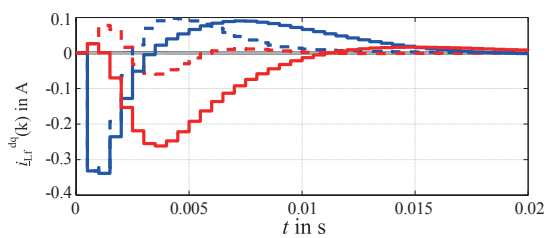

Parameters from Fig. 8

Excitation: 1A Command Step 1V Disturbance

(b)

Fig. 9. Command response (a) and disturbance response (b).

no decoupling measures are applied, the dominating pole pair is significantly shifted and rotated. In addition, both poles are not complex conjugated anymore. This phenomenon of complex poles without conjugated counterparts occurs as a consequence of the complex SISO system with significant crosscoupling between $\mathrm{d}$ - and q-axis. This crosscoupling between $\mathrm{d}$ - and qcurrent and voltages can be observed from the disturbance step response of the system in Fig. 9. If the quasi stationary decoupling structure proposed on Fig. 7 is applied, the poles in Fig. 8 slightly move back towards their ideal complex conjugated placement. As a result, the excitation of the current in the q-axis is significantly reduced and also the d-axis current settles much faster. A similar effect can be observed looking at the command response of the regulator in Fig. 9.

This investigation shows that the proposed decoupling structures significantly improves the system dynamics, but cannot entirely eliminate the crosscoupling between $\mathrm{d}$ - and q-axis. To optimize the PI regulator feedback gains, in the next section it is shown dynamics of the cross coupled system can be taken into account in the regulator design, which is not possible following the symmetrical optimum design rule.

\section{Trajectory Generation and Command Feedforward}

Before the focus is set to the more accurate design of the regulator, for the improvement of the command tracking performance a consistent command trajectory filter is added to the control, which is depicted in Fig. 7. It consists of a model of the physical system, in this case an inductor, with a feedback path. The feedback gain $K_{\mathrm{f}}$ is selected to adjust the bandwidth of the generated current reference and command feedforward voltage. The command trajectory is constraint to the available voltage margin to ensure that any voltage command from the controller remains within the system limits, i.e. $\left|\underline{v}_{\mathrm{m}}{ }^{\mathrm{dq}}\right|<V_{\mathrm{dc}} / \sqrt{3}$. Consequently, the resulting current reference is always feasible. In addition, a voltage command $\underline{v}_{\text {cff }}^{\text {dq }}$ is generated, which is directly passed as a feedforward to the voltage modulator. Note that it is very important to delay the current reference by one sampling step, as shown in Fig. 7, to ensure that the applied command feedforward voltage $\underline{v}_{\text {cff }}{ }^{\text {dq }}$ leads to the desired current at the exact time instant when the corresponding current reference is

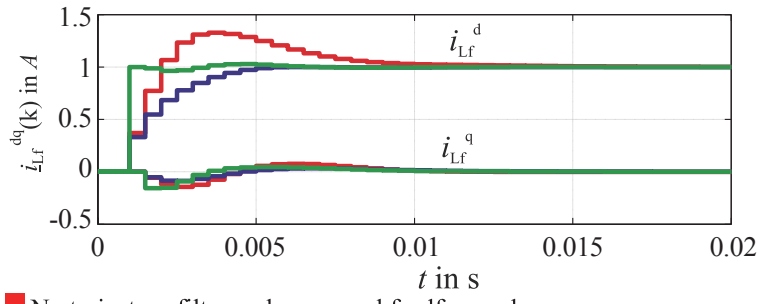

No trajectory filter and command feedforward

With trajectory filter $\left(w_{\mathrm{TF}}=1 /\left(3 T_{\mathrm{s}}\right)\right)$ and command feedforward

With trajectory filter $\left(f_{\mathrm{TF}}=1 / T_{\mathrm{s}}\right)$ and command feedforward (System and Control Parameters from Fig. $8 K_{\mathrm{f}}=L_{\mathrm{f}} f_{\mathrm{Tf}}$ )

Fig. 10. Command tracking with different command filter bandwidths.

applied.

As a result of the command filter and the feedforward path, the control error stays zero during command tracking transients. Consequently, the controller just needs to compensate disturbances and model inaccuracies and it can be designed for disturbance rejection only. The command tracking bandwidth can be set with the gain of the command trajectory filter independent of the controller. In Fig. 10 the command response with and without command filter and command feedforward are compared. It can be seen that these measures eliminate the overshoot during transients and allow to achieve deadbeat command tracking within 2 time steps.

\section{Discrete Time Regulator Design}

In this section, the efficient implementation of synchronous-frame proportional integral (SFPI) regulators, proportional-resonant (PR) regulators and higher order current regulators is discussed. It is illustrated how to optimize the design of these control structures. After an optimization, the PR and SFPI regulator are compared to outline advantages and disadvantages of both for different application areas.

\section{A. Implementation Options for Current Regulators}

The SFPI regulator (19) is usually designed and implemented in the synchronous reference frame

$$
\underline{G}_{\operatorname{SFPI}}(z)^{\mathrm{dq}}=K_{\mathrm{p}}+\frac{K_{\mathrm{i}} T_{\mathrm{s}}}{1-z^{-1}}=K_{\mathrm{p}}\left(1+\frac{K_{\mathrm{i}} T_{\mathrm{s}}}{K_{\mathrm{p}}} \frac{1}{1-z^{-1}}\right) .
$$

However, the design and the implementation of the regulator can be done in any other reference frame achieving identical system dynamics: For example, in [13], the continuous time domain SFPI regulator has been implemented in the stationary reference frame. This can also be done for the discrete time control structure, presented in Fig. 7 using the discrete time coordinate transformation given by (8). The entire control structure from Fig. 7 implemented in the stationary frame is shown in Fig. 8. For the SFPI regulator the transformation leads to

$$
\underline{G}_{\operatorname{SFPI}}(z)^{\alpha \beta}=K_{\mathrm{p}}+\frac{K_{\mathrm{i}} T_{\mathrm{s}}}{1-\mathrm{e}^{\mathrm{j} \omega_{\mathrm{e}} T_{\mathrm{s}}} z^{-1}} .
$$

This expression exhibits a resonator for space vectors, which 
is therefore called space-vector resonator. It results from the integrator which is shifted from the dq- into the $\alpha \beta$-coordinate system and guarantees the control of the current at its resonant frequency with infinite stiffness and zero steady state error due to the internal model principle. It can be efficiently implemented on a DSP similar to a discrete time integrator as complex difference equation using the backshift operator of the z-transform:

$$
\begin{aligned}
\underline{v}_{\mathrm{SFPI}, \mathrm{reg}}{ }^{\alpha \beta}(k) & =K_{\mathrm{p}} \Delta \underline{\underline{i}}_{\mathrm{Lf}}^{\alpha \beta}(k)+\underline{v}_{\mathrm{res}}{ }^{\alpha \beta}(k) \\
\underline{v}_{\mathrm{res}}{ }^{\alpha \beta}(k) & =K_{\mathrm{i}} T_{\mathrm{s}} \Delta \underline{L}_{\mathrm{Lf}}^{\alpha \beta}(k)+\underline{v}_{\mathrm{res}}{ }^{\alpha \beta}(k-1) \mathrm{e}^{\mathrm{j} \omega_{\mathrm{e}} T_{\mathrm{s}}}
\end{aligned}
$$

The stationary frame implementation of grid current regulators brings the benefit of a very simple and efficient implementation without any reference frame transformation.

Based on this concept, a PI regulator on the positive sequence and one on the negative sequence of the current can be combined in the stationary frame resulting in the discrete time implementation of the so called proportional-resonant (PR) regulator [2], which ensures the rejection of positive and negative sequence voltage disturbances:

$$
\begin{aligned}
& \underline{G}_{\mathrm{PR}}(z)^{\alpha \beta}=K_{\mathrm{p}}+\frac{K_{\mathrm{i}}^{+} T_{\mathrm{s}}}{1-\mathrm{e}^{\mathrm{j} \omega_{\mathrm{e}} T_{\mathrm{s}}} z^{-1}}+\frac{K_{\mathrm{i}} T_{\mathrm{s}}}{1-\mathrm{e}^{-\mathrm{j} \omega_{\mathrm{e}} T_{\mathrm{s}}} z^{-1}} \\
& K_{\mathrm{i}}^{-}=\stackrel{K_{\mathrm{i}}^{+}}{\rightarrow}=K_{\mathrm{i}} K_{\mathrm{p}}+\frac{2 K_{\mathrm{i}} T_{\mathrm{s}}\left(1-\cos \left(\omega_{\mathrm{e}} T_{\mathrm{s}}\right) z^{-1}\right)}{1-2 \cos \left(\omega_{\mathrm{e}} T_{\mathrm{s}}\right) z^{-1}+z^{-2}} .
\end{aligned}
$$

Consequently, an arbitrary number of SFPI regulators can be implemented in the stationary frame as space-vector resonators, which guarantee infinite stiffness and zero steady state error on multiple harmonics e.g. on the dominant $-5^{\text {th }}, 7^{\text {th }},-11^{\text {th }}$ and $13^{\text {th }}$ grid harmonic. This controller framework is referred to as resonant space-vector (RSV) regulator in the following:

$$
G_{\mathrm{RSV}}(z)^{\alpha \beta}=\frac{\underline{\underline{V}}_{\mathrm{reg}}^{\mathrm{dq}}(z)}{\underline{\Delta} i_{\mathrm{Lf}}^{\mathrm{dq}}(z)}=K_{\mathrm{p}}+\sum_{\mathrm{n}=-\mathrm{k}}^{\mathrm{k}} \frac{K_{\mathrm{i}, \mathrm{n}} T_{\mathrm{s}}}{1-z^{-1} \mathrm{e}^{\mathrm{j} \omega_{\mathrm{e}} \mathrm{T}_{\mathrm{s}}}}
$$

For a digital implementation, the difference equations of the RSV regulator can be formulated analogously to (21). To compensate the delay of the update and latch at higher harmonics it is advisable to include a phase shift into the gain of each resonator, which results in (24). This measure enhances damping and stability of the closed loop system.

$$
G_{\mathrm{RSV}}(z)^{\alpha \beta}=K_{\mathrm{p}}+\sum_{\mathrm{n}=-\mathrm{k}}^{\mathrm{k}} \frac{K_{\mathrm{i}, \mathrm{n}} T_{\mathrm{s}}}{1-z^{-1} \mathrm{e}^{\mathrm{j} \omega_{\mathrm{e}} \mathrm{T}_{\mathrm{s}}}} \mathrm{e}^{\mathrm{j} 2(\mathrm{n}-1) \omega_{\mathrm{e}} \mathrm{T}_{\mathrm{s}}}
$$

\section{B. Design and Comparison of SFPI and PR regulators}

It has been discussed in section III that the regulator design only needs to focus on providing robustness as well as a fast and strong disturbance rejection ability. This requires the feedback regulator design to include the correct model as well as the already discussed quasi stationary decoupling measures. In most publications, a quasi-continuous design of the regulator, which has conveniently been used in section III, is applied. This is usually based on the symmetrical optimum [3] or the phase margin [8]. Unfortunately, this does not allow insight into the design process if a system with certain crosscoupling between dand q-components is given.

To overcome this limitation, this work proposes the generalization of the root-locus method, which has previously only been used for transfer functions with scalar coefficients, to transfer functions with complex coefficients. Thereby, it is applicable for the discussed design task. In case of the SFPI regulator, a state feedback decoupling according to Fig. 11 is applied. However, if the PR regulator is used, a decoupling is not meaningful, because typically neither negative nor positive sequence should not be preferred. The following regulator design of the three phase PWM converter, modeled as complex SISO system, picks up on the root-locus design metric presented in [7]. To achieve insights into the regulator design options for SFPI (20) and PR regulator (22) in Fig. 12 the root loci of the open loop transfer function (25) is plotted for various gains $r_{\tau}=K_{\mathrm{i}} T_{\mathrm{s}} /$ $K_{\mathrm{p}}$ of both regulators.

$$
\underline{G}_{0}(z)^{\alpha \beta}=\underline{G}_{\text {plant }}(z)^{\alpha \beta} K_{\mathrm{p}}\left\{\begin{array}{c}
\left(1+\frac{K_{\mathrm{i}} T_{\mathrm{s}}}{K_{\mathrm{p}}} \frac{1}{\left.1-\mathrm{e}^{\mathrm{j} \omega_{\mathrm{e}} T_{\mathrm{s}} z^{-1}}\right)}\right) \\
\left(1+\frac{K_{\mathrm{i}} T_{\mathrm{s}} 2\left(1-\cos \left(\omega_{\mathrm{e}} T_{\mathrm{s}}\right) z^{-1}\right)}{K_{\mathrm{p}} 1-2 \cos \left(\omega_{\mathrm{e}} T_{\mathrm{s}}\right) z^{-1}+z^{-2}}\right)
\end{array}\right.
$$

Due to the complex transfer function of plant and regulator the root loci are not complex conjugated with respect to each other. It is the design goal to find a controller with high bandwidth and disturbance rejection ability that does neither causes significant overshoot nor excites resonances. Thus, it is required to

- Maximize the dynamic stiffness $\left|\underline{V}_{\text {grid }}{ }^{\mathrm{dq}}(j \omega) / \underline{I}_{\mathrm{Lf}}{ }^{\mathrm{dq}}(j \omega)\right|$

- Keep the damping in the range of $\xi_{\text {opt }}>1 / \sqrt{2}$.

To optimize the regulator with respect to these design goals for each root locus the open loop gain is maximized via $K_{\mathrm{p}}$ until the damping constraint $\xi_{\text {opt }}>1 / \sqrt{2}$ is hit. The resulting final poles are marked with black crosses in Fig. 12. They all lead to a design of the proportional state feedback gain with $K_{\mathrm{p}} \approx L_{\mathrm{f}} /$ $\left(3 T_{\mathrm{s}}\right)$. For these designs the dynamic stiffness and the disturbance step response are also plotted in Fig. 12. The dynamic stiffness is used to evaluate the disturbance response properties in the frequency domain, as it indicates what disturbance voltage it takes at each frequency to change the current at that frequency by $1 \mathrm{~A}$. To find the optimal regulator, the design scenario with the highest tuning factor that still keeps the damping constraint is selected. Thereby, it is guaranteed that the stiffness around grid frequency is maximized, which is desired to ensure a fast rejection of disturbances at the fundamental frequency and a certain robustness with respect to grid frequency variations. The design shown in red for $r_{\tau, \mathrm{SPPI}}=0.16$ and $r_{\tau, \mathrm{PR}}=0.08$ is a design optimum. A bigger $r_{\tau}$ would lead to undesirable lower damping and overshoot. The resulting optimized feedback gains, which are universally applciable for this current control structure, are summarized in TABLE I. 


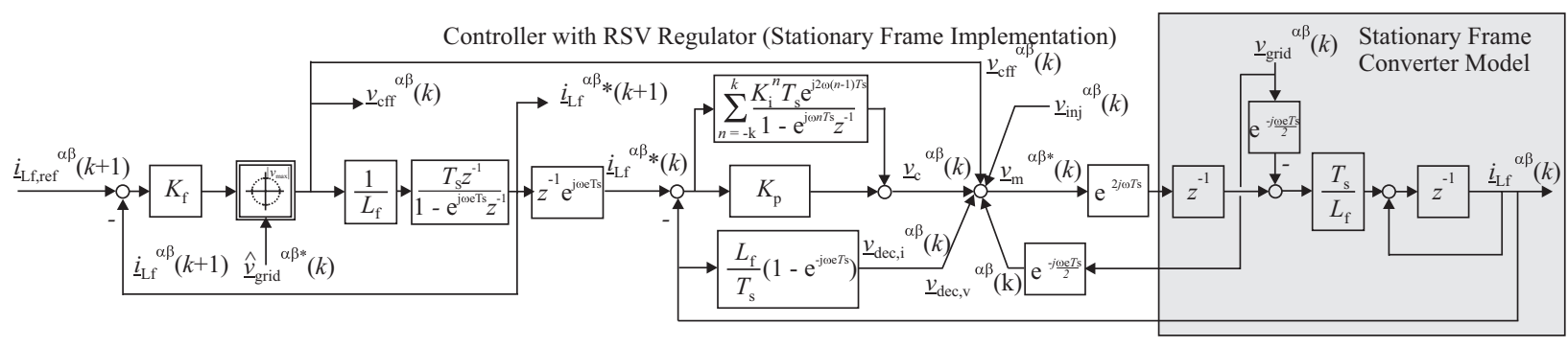

Fig. 11. State block diagram of the discrete time current control structure implemented in the stationary frame.
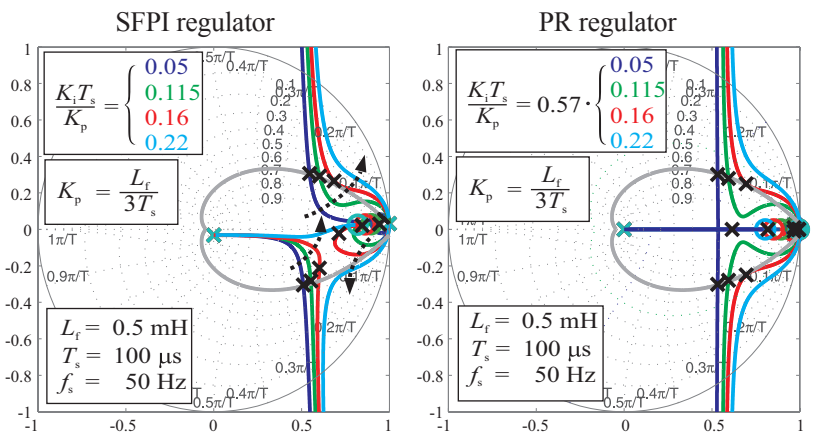

(a)

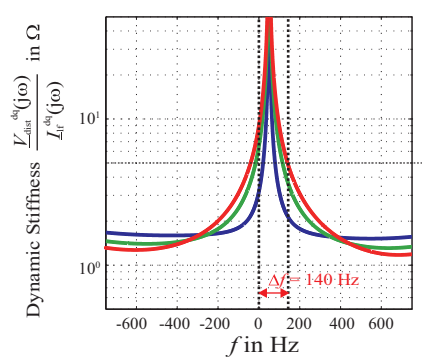

(b)
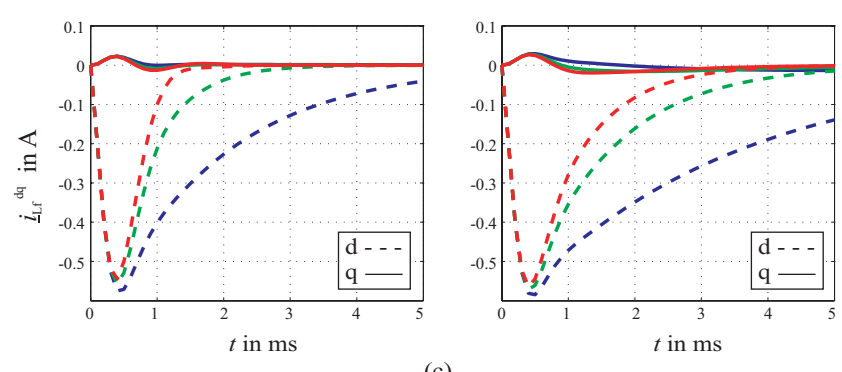

(c)

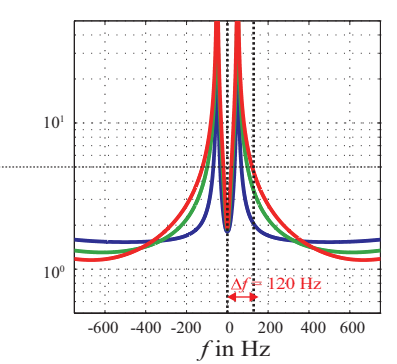

)

Fig. 12. Control design of the complex SISO system based on (a) Root locus plot of the complex SISO system, (b) double sided dynamic stiffness plot, (c) disturbance response to $1 \mathrm{~V}$ step in the d-axis.

An important question to be answered is if there is any benefit from using the PR or the SFPI regulator. From the optimized design it is clear that if no control of the negative component is necessary, the SFPI regulator is always a better choice. The reason for this is that, given similar damping constraints, the SFPI regulator can be built with a higher resonant gain $K_{\mathrm{i}}$ and thus provides as faster settling time after disturbances in the fundamental grid voltage. If both regulators are analyzed over a sampling frequency range from $1 \mathrm{kHz}$ to $20 \mathrm{kHz}$, which is used in most medium and high power application, the advantage of the SFPI regulator over the PR regulator nearly entirely vanishes at
TABLE I

Optimized Feedback Gains for SFPI and PR Regulator

\begin{tabular}{ccc}
\hline \hline Gains & SFPI Regulator & PR Regulator \\
\hline$K_{\mathrm{p}}$ & $L_{\mathrm{f}} /\left(3 T_{\mathrm{s}}\right)$ & $L_{\mathrm{f}} /\left(3 T_{\mathrm{s}}\right)$ \\
$K_{\mathrm{i}}=K_{\mathrm{r}}$ & $0.16 \cdot K_{\mathrm{p}} / T_{\mathrm{s}}$ & $0.08 \cdot K_{\mathrm{p}} / T_{\mathrm{s}}$ \\
\hline \hline
\end{tabular}

very low sampling frequencies. which has been illustrated in [22] in detail.

\section{Design and Implementation of the RSV Regulator}

The introduced RSV regulator is a compact way to formulate a regulator on multiple harmonics. One limitation of higher order regulator structures is that it is not intuitive to design multiple state feedback gains such that the overall system dynamics are stable, provide reasonable bandwidth and are well behaved. To overcome this limitation, it is shown how the root-locus method for complex SISO systems can be used to optimize the state feedback gains of multiple space vector resonators. A properly tuned SFPI regulator is used as a starting point that is augmented by space vector resonators achieving infinite stiffness at the $-5^{\text {th }},+7^{\text {th }},-11^{\text {th }}$ and $+13^{\text {th }}$ grid harmonic.

The design goal for the entire regulator is to augment the bandwidth of high stiffness around the desired frequencies while keeping the effective damping of the system above a certain level such that resonance do not become dominant. First, the RSV regulator state feedback gains rejecting the $-5^{\text {th }}$ and $+7^{\text {th }}$ grid voltage harmonic are synthesized. The gain on $-5^{\text {th }}$ and $+7^{\text {th }}$ harmonic are kept identical $\left(K_{\mathrm{i},+5}=K_{\mathrm{i},-7}=K_{\mathrm{r},-5,+7}\right)$ to limit the complexity of the design. The root locus in Fig. 13 (left) shows the possible pole placements for an increasing $K_{\mathrm{r}, 5,+7}$. For the red and black marked poles two design options are shown in detail, whose dynamic stiffness plot is shown below in comparison to the dynamic stiffness of the pure SFPI regulator used as starting point. The poles resulting from the space vector resonators on the $-5^{\text {th }}$ and $+7^{\text {th }}$ harmonic, which are close to the stability margin, are balanced by zeros and are not critical for the design as long as they remain stable. The same is true for the critically damped pole on the real axis. However, when increasing the $K_{\mathrm{r},-5,+7}$ gains the poles resulting from the proportional state feedback path are further pulled to weaker damping. Thus, the design decision for $K_{\mathrm{r}, 6}$ is a compromise between high system damping and a bigger bandwidth of the resonant state feedback 

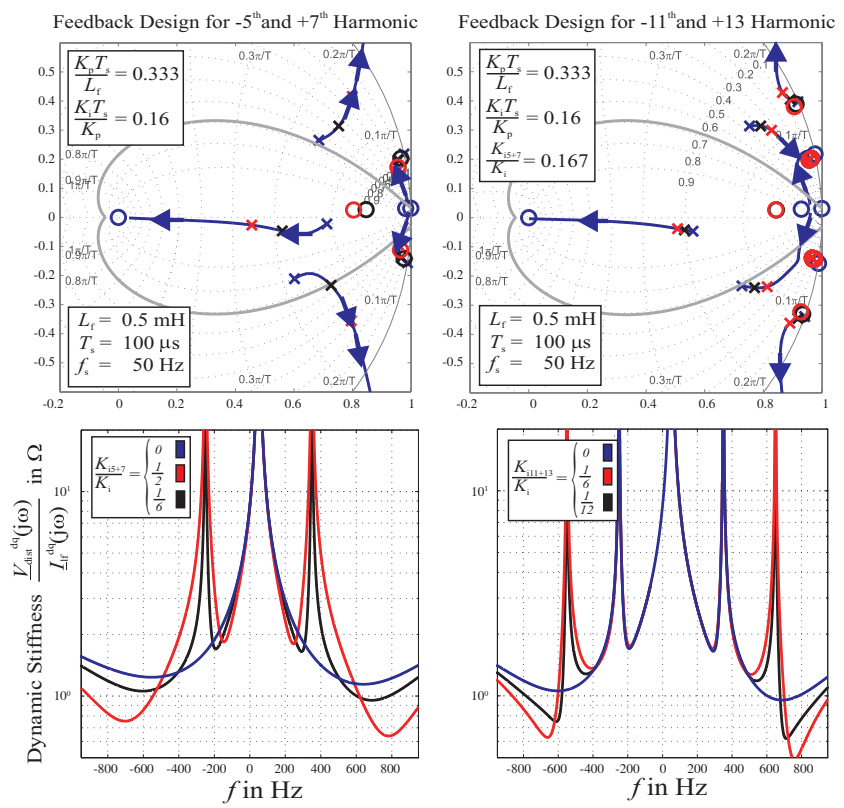

Fig. 13. Design of the RSV regulator with $-5^{\text {th }},+7^{\text {th }}-11^{\text {th }}$ and $13^{\text {th }}$ harmonic based on the root-locus method.

loop. This is illustrated for two cases: $K_{\mathrm{r}, 5,6} / K_{\mathrm{i}}=1 / 2$ and $1 / 6$. As $K_{\mathrm{r}, 5,6} / K_{\mathrm{i}}=1 / 2$ reduces the damping quiet significantly resulting in a reduction of the worst case stiffness by a factor of 2 , a design with $K_{\mathrm{r}, 6} / K_{\mathrm{i}}=1 / 6$ is a reasonable choice.

After the successful resonant state feedback loop design of the $-5^{\text {th }}$ and $+7^{\text {th }}$ harmonic, the resulting closed loop system dynamics are used as starting point to design the $-11^{\text {th }}$ and $+13^{\text {th }}$ harmonic resonant feedback loop. The root locus for an increasing $\left(K_{\mathrm{i},-11}=K_{\mathrm{i},+13}=K_{\mathrm{i}, 11,+13}\right)$ depicted in Fig. 13 (right) shows that this time the complex conjugated pole pair corresponding to the proportional state feedback loop is not leading to weak damping. The critically damped pole and also the poles resulting from the space vector resonator on $5^{\text {th }}$ and $7^{\text {th }}$ harmonic do not limit the feedback gain. However, the pole resulting from the additional space vector resonators on the $-11^{\text {th }}$ and $+13^{\text {th }}$ harmonic reveal a low system damping for higher values of $K_{\mathrm{i}, 11,+13}$. This effect is a result from the growing distance and weaker balancing between pole and zero. Thus, a design with $K_{\mathrm{r}, 5,+7} / K_{\mathrm{i}}=1 / 6$, marked in red, is not desirable as it results in a very weakly damped pole close to the unity circle, whereas state feedback gains of $K_{\mathrm{i},-11,+13} / K_{\mathrm{i}}=1 / 12$ seem to be a good design compromise. This exemplary design shows how a RSV regulator structure is designed systematically and consistently generalizing the root locus method for complex SISO system.

\section{Simulation AND EXPERIMENTAL Results}

Based on the introduced control framework a current control structure according to Fig. 11 has been designed and implemented in $\mathrm{C}++$. It was first tested on a Software-in-the-Loop (SiL) test bench using MATLAB Simulink and PLECS. Afterwards, the control classes were implemented on an AixControl XCS2000 rapid control prototyping system to evaluate the con-

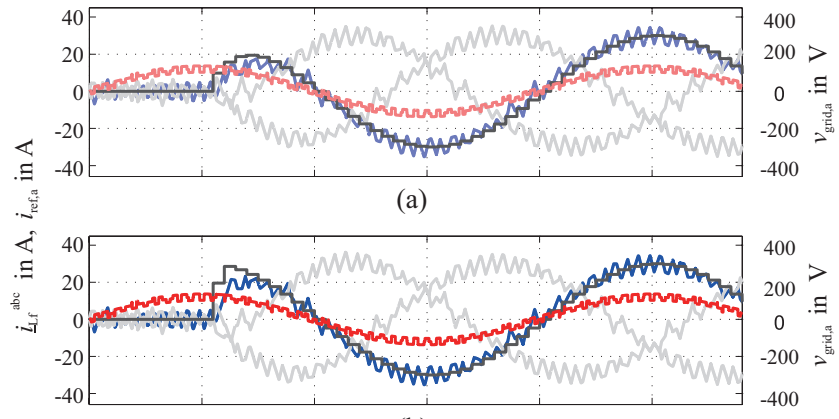

(b)

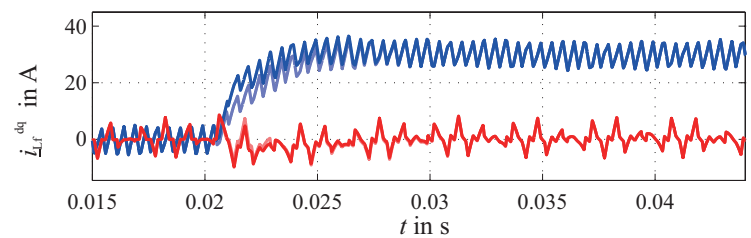

(c)

Fig. 14. Simulation of the command response with a trajectory generator gain $K_{\mathrm{f}}=L \mathrm{f} /(3 T \mathrm{~s})\left(\right.$ a) and $K_{\mathrm{f}}=L \mathrm{f} / T \mathrm{~s}$.

trol algorithm experimentally.

\section{A. Evaluation of the Command Tracking Performance}

First, the performance of the SFPI regulator and the command filter is investigated for the system parameters summarized as Setup I in TABLE II. The simulation in Fig. 14 shows the system command response. The trajectory generator, which includes the voltage limit, shapes a feasible current command and applies a consistent command feedforward leading to a high command tracking bandwidth without overshoot. With the gain of the trajectory generator $K_{\mathrm{f}}$ the bandwidth of the system can be properly adjusted independent of the regulator gains. The simulation results can nearly perfectly be transferred to the experiment, which is shown in Fig. 15. The major difference in current between simulation and experiment occurs due to a small grid voltage imbalance and minor pulsations of the dclink. This shows that an accurate simulation of a grid tied PWM converter reaches nearly the precision of an experimental setup.

\section{B. Comparison of SFPI and PR Regulator}

It has been discussed in Section IV B that the PR regulator gains needs to be detuned compared to the SFPI regulator to keep a desired damping level. As a consequence, the regulator analysis showed that the SFPI regulator can provide a higher stiffness compared to the PR regulator. The PR and the SFPI regulator are designed according to section IV for an experimental demonstration. To keep the damping at $\xi=0.707$ the resonant feedback gain of the PR regulator needed to be set to approximately $1 / 2$ of the resonant feedback gain of the SFPI regulator.

To analyze and compare the disturbance rejection performance of both regulators a chopped load resistance is transiently applied in series to the filter of the converter. The parameters of the experimental setup are summarized in TABLE II. (Setup 
TABLE II

Parameters of the Three Experimental Setups

\begin{tabular}{ccccccccc}
\hline & $L_{\mathrm{f}}$ & $L_{\text {grid }} / R_{\text {chop }}$ & $f_{\text {pwm }}$ & $T_{\mathrm{s}}$ & $V_{\mathrm{dc}}$ & $V_{\text {grid,l-n }}$ & $K_{\mathrm{p}}$ & $K_{\mathrm{i}}$ \\
\hline Setup I & $2 \mathrm{mH}$ & $0.2 \mathrm{mH}$ & $1 \mathrm{kHz}$ & $500 \mu \mathrm{s}$ & $300 \mathrm{~V}$ & $130 \mathrm{~V}$ & $1.33 \Omega$ & $K_{\mathrm{i}}=426 \Omega / \mathrm{s}$ \\
Setup II & $0.5 \mathrm{mH}$ & $1 \Omega$ & $5 \mathrm{kHz}$ & $100 \mu \mathrm{s}$ & $250 \mathrm{~V}$ & - & $1.7 \Omega$ & variable \\
Setup III & $2 \mathrm{mH}$ & $0.2 \mathrm{mH}$ & $4 \mathrm{kHz}$ & $250 \mu \mathrm{s}$ & $420 \mathrm{~V}$ & $200 \mathrm{~V}$ & $2.6 \Omega$ & $1750 \Omega / \mathrm{s}$ \\
\hline \hline
\end{tabular}

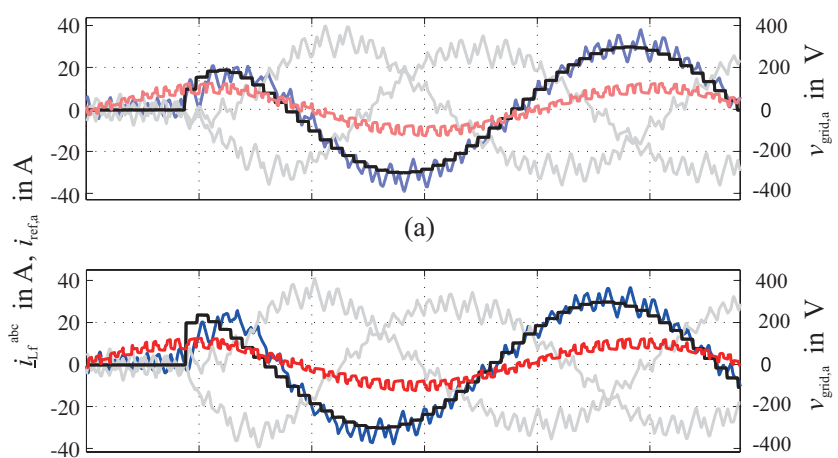

(b)

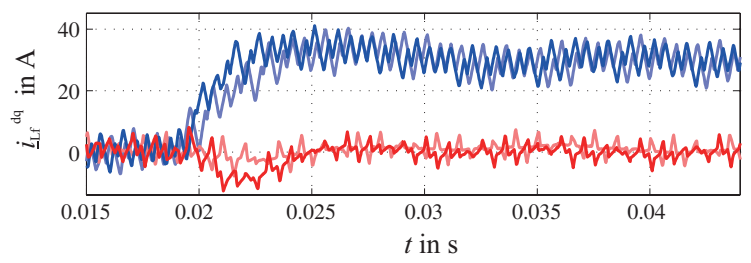

(c)

Fig. 15. Measurement results of the command response with a trajectory generator gain $K_{\mathrm{f}}=L \mathrm{f} /(3 T \mathrm{~s})$ (a) and $K_{\mathrm{f}}=L \mathrm{f} / T \mathrm{~s}$.
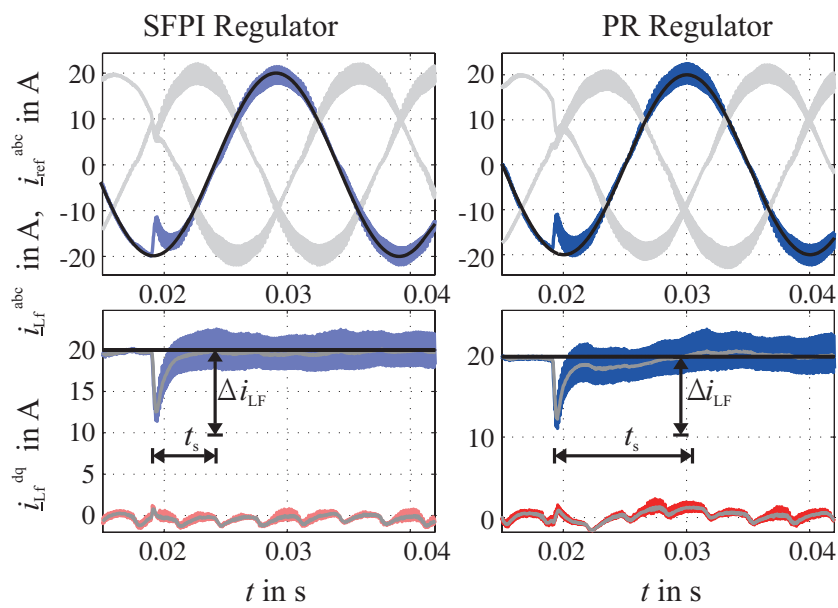

Fig. 16. Measured response of the SFPI $\left(K_{\mathrm{i}}=2500 \Omega / \mathrm{s}\right)$ and the PR regulator $\left(K_{\mathrm{r}}=1400 \Omega / \mathrm{s}\right)$ to a chopped resistive load of $1 \Omega$ that is transiently connected in series to the inductance.

II) and the measurement resutls are illustrated in Fig. 16. The current sag $\Delta i_{\mathrm{Lf}}$ that can be observed for both controllers are identical. This is because of the equal proportional feedback gains. However, the PR regulator needs more than twice the settling time $t_{\mathrm{s}}$ compared to the SFPI regulator due to the reduced

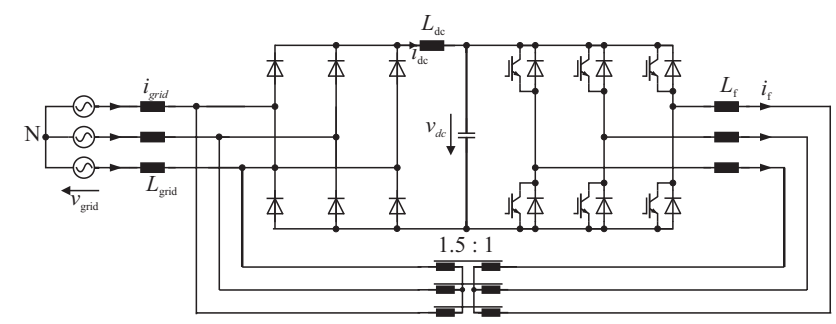

Fig. 17. Experimental setup for performance evaluation of the resonant space vector.

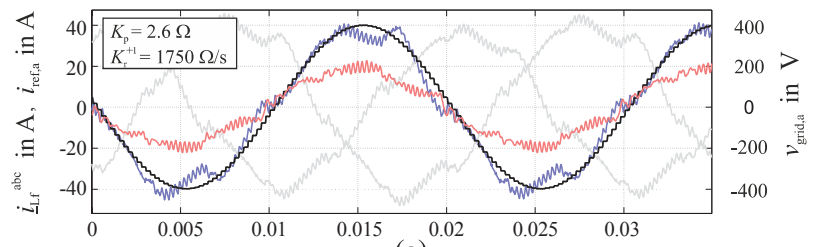

(a)

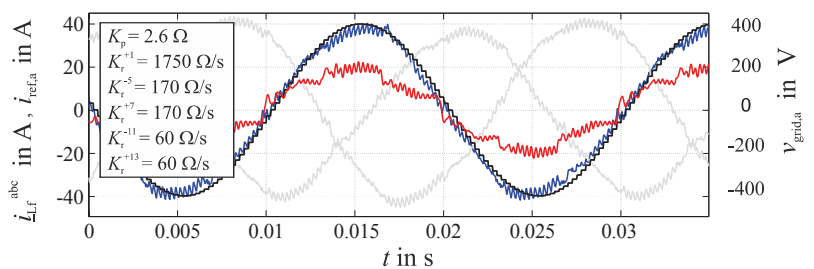

(b)

Variables:

Phase Current

Reference Current

Phase Voltage

Experimental Setup:

$L_{\mathrm{f}}=2 \mathrm{mH}$

$f_{\mathrm{pwm}}=4 \mathrm{kHz}$

$T_{\mathrm{s}}=250 \mu \mathrm{s}$

$V_{\mathrm{dc}}=420 \mathrm{~V}$

Fig. 18. Experimental comparison of the SFPI regulator only (top) and the resonant space vector regulator structure with state feedback on the $1^{\text {st }}, 5^{\text {th }}$, $7^{\text {th }}, 11^{\text {th }}$ and $13^{\text {th }}$ harmonic (down) under distorted grid conditions.

resonant feedback gain. This reveals, that the SFPI regulator is more effective for most current controllers. Only if the rejection of negative sequence voltages is required, e.g. in the case of grid imbalances, the PR regulator is a better choice, as it can entirely reject negative sequence voltage disturbances.

\section{Multiple Harmonic Rejection With the RSV Regulator}

Finally, the ability of the resonant space vector regulator to reject multiple harmonics is evaluated experimentally. Therefore, the active converter (TABLE II Setup III) is paralleled with a passive three phase rectifier, as illustrated in Fig. 17. This 
specific setup allows operating the PWM converter at a grid with artificially excited grid harmonics.

In Fig. 18 the performance of the SFPI regulator structure and the resonant space vector regulator structure are compared under these grid conditions with artificially excited grid harmonics. In case of the SFPI regulator, the grid voltage harmonics excite the current, in particular the $5^{\text {th }}, 7^{\text {th }}, 11^{\text {th }}$ and $13^{\text {th }}$ harmonic. This is because the SFPI current regulator exhibits a finite stiffness at these harmonics, which can be seen in Fig. 12. Therefore, it cannot entire reject this disturbance voltage. However, the fundamental harmonic is controlled such that it accurately follows the current reference in amplitude and phase.

In contrast, the space vector regulator structure, which enhances the single space-vector resonator of the SFPI regulator by additional higher order space-vector resonators, rejects the higher order voltage harmonics due to the infinite stiffness at the higher order harmonics. As a consequence, the regulated current is purely sinusoidal and smoothly follows the reference. This elimination of the high order current harmonics is of great importance, especially if multiple converters are operated at a weak utility grid, because it prevents a stronger excitation of the voltage harmonics that is reflected at the coupling point of the converters.

\section{CONCLUSION}

In this work, an insightful design and implementation methodology for discrete-time current control of PWM converters has been proposed and analyzed. Therefore, an accurate discrete-time model for the control of a three-phase converter has been derived. This has been used to develop proper decoupling paths and a consistent command filter structure. The root-locus method has been generalized for the control design of SISO systems with complex coefficeints and used to optimize the SFPI and the PR regulators for three-phase current control. Thereby, both regulator structures have been compared systematically. Based on the SFPI implementation in the stationary frame, the resonant space-vector regulators concept has been developed. It allows to handle various regulators e.g. SFPI, PR and regulators on multiple harmonic in one framework leading to consistent tuning and an efficient implementation. Experimental results are presented to validate the introduced control implementation and design framework.

\section{REFERENCES}

[1] D. Schauder and R. Caddy, "Current control of voltage-sourceinverters for fast four-quadrant drive performance," IEEE Transactions on Industry Applications, vol. IA-18, pp. 163-171, Mar./Apr. 1982.

[2] D. N. Zmood, D. G. Holmes, and G. H. Bode, "Frequency-domain analysis of three-phase linear current regulators," IEEE Transactions on Industry Applications, vol. 37, no. 2, pp. 601-610, Mar./Apr. 2001.

[3] V. Blasko, V. Kaura, "A new mathematical model and control of a three-phase AC-DC voltage source converter," IEEE Transactions on Power Electronics, vol. 12, no. 1, pp. 116-123, Jan. 1997.

[4] S. A. Richter and R. W. De Doncker, "Digital proportional-resonant (PR) control with anti-windup applied to a voltage-source inverter," in Proc. 14th Eur. Conf. Power Electron. Appl., 2011, pp. 1-10.

[5] K. Hongrae, M. W. Degner, J. M. Guerrero, F. Briz, and R. D. Lorenz,
"Discrete-time current regulator design for AC machine drives," IEEE Transactions on Industry Applications, vol. 46, no. 4, pp. 1425-1435, Jul.-Aug. 2010.

[6] S. A. Richter, J. von Bloh, C. P. Dick, D. Hirschmann, and R. W. De Doncker, "Control of a medium-voltage test generator," in IEEE Power Electronics Specialists Conference 2008, 2008, pp. 3787-3793.

[7] C. H. van der Broeck, R.W. De Doncker, S. A. Richter, and J. von Bloh, "Unified control of a buck converter for wide load range applications," in IEEE APEC 2014, March 2014, pp. 2788-2795.

[8] J. Shen, S. Schröder, H. Stagge, and R. W. De Doncker, "Precise modeling and analysis of DQ-frame current controller for high power converters with low pulse ratio," in IEEE Energy Conversion Congress and Exposition, September 2012, Raleigh, NC, USA.

[9] P. Mattavelli, "A closed-loop selective harmonic compensation for active filters," IEEE Transactions on Industry Applications, vol. 37, no. 1, pp. 81-89, Jan./Feb. 2001.

[10] M. Hausmann, N. Grass, and B. Piepenbreier, "Harmonic compensation in a load emulation system using different control techniques," in IEEE 34th International Telecommunications Energy Conference INTELEC, Sept. 30-Oct. 4, 2012, pp. 1-7.

[11] S. Engel, K. Rigbers, and R. W. De Doncker, "Digital repetitive control of a three-phase flat-top-modulated grid tie solar inverter," in 13th European Conference on Power Electronics and Appl., EPE '09, 8-10 Sept., 2009, pp. 1-10.

[12] P. Schülting, C. H. van der Broeck, and R. W. De Doncker, "A generalized control design approach for a repetitive controller on current harmonics," in 2015 IEEE 16th Workshop on Control and Modeling for Power Electronics (COMPEL), Vancouver, BC, 2015, pp. 1-8.

[13] T. M. Rowan and R. J. Kerkman, "A new synchronous current regulator and an analysis of current-regulated PWM inverters," IEEE Transactions on Industry Applications, vol. IA-22, no. 4, pp. 678-690, July 1986.

[14] F. B. del Blanco, M. W. Degner, and R. D. Lorenz, "Dynamic analysis of current regulators for AC motors using complex vectors," IEEE Transactions on Industry Applications, vol. 35, no. 6, pp. 1424-1432, Nov./Dec. 1999.

[15] F. Briz, M. W. Degner, and R. D. Lorenz, "Analysis and design of current regulators using complex vectors," IEEE Transactions on Industry Applications, vol. 36, no. 3, pp. 817-825, May/Jun. 2000.

[16] S. Gataric and N. R. Garrigan, "Modeling and design of three-phase systems using complex transfer functions," in Proc. IEEE Power Electron. Spec. Conf., vol. 2, June/July 1999, pp. 691-697.

[17] L. Harnefors, "Modeling of three-phase dynamic systems using complex transfer functions and transfer matrices," IEEE Transactions on Industrial Electronics, vol. 54, no. 4, pp. 2239-2248, Aug. 2007.

[18] G. D. Holmes and T. Lipo, "Pulse width modulation for power converters - principles and practice," IEEE Press Series on Power Engineering, Piscataway, NJ, USA: John Wiley and Sons.

[19] V. Blasko and V. Kaura, "A novel control to actively damp resonance in input LC filter of a three phase voltage source converter," in IEEE APEC 1996, vol. 2, 3-7 Mar. 1996, pp. 545-551.

[20] H. van der Broeck, H. Skudelny, and G. Stanke, "Analysis and realization of a pulse width modulator based on voltage space vectors," IEEE Transactions on Industry Applications, vol. 24, no. 1, pp. 142150, Jan./Feb. 1988

[21] O. Kukrer, "Discrete-time current control of voltage-fed three-phase PWM inverters," IEEE Transactions on Power Electronics, vol. 11, no. 2, pp. 260-269, Mar 1996.

[22] C. H. van der Broeck, R. W. De Doncker, S. A. Richter, and J. von Bloh, "Discrete time modeling, implementation and design of current controllers," in 2014 IEEE Energy Conversion Congress and Exposition (ECCE), Pittsburgh, PA, 2014, pp. 540-547.

[23] R. Isermann, "Digital control systems", vol. 1, Springer Press 1989.

[24] S. Buso and P. Mattavelli, "Digital control in power electronics," Lectures of Power Electronics Morgan \& Claypool Publishers, 2006.

[25] C. H. van der Broeck, M. Biskoping, and R. W. De Doncker, "Discrete time control design of three phase PWM rectifiers," in 2015 17th European Conference on Power Electronics and Applications (EPE'15 ECCE-Europe), Geneva, 2015, pp. 1-10.

[26] J. He, Y. W. Li, F. Blaabjerg, and X. Wang, "Active harmonic filtering using current-controlled, grid-connected DG units with closed-loop 
power control," IEEE Transactions on Power Electronics, vol. 29, no. 2, pp. 642-653, Feb. 2014

[27] P. Schuelting, C. H. van der Broeck, and R. Doncker, "Analysis and design of repetitive controllers for applications in distorted distribution grids," IEEE Transactions on Power Electronics, 2018.

[28] M. Rosekeit, C. van der Broeck, and R. W. De Doncker, "Dynamic control of a dual active bridge for bidirectional AC charging," in 2015 IEEE International Conference on Industrial Technology (ICIT), Seville, 2015, pp. 2085-2091.

[29] N. Hoffmann, F. W. Fuchs, M. P. Kazmierkowski, and D. Schröder, "Digital current control in a rotating reference frame - Part I: System modeling and the discrete time-domain current controller with improved decoupling capabilities," IEEE Transactions on Power Electronics, vol. 31, no. 7, pp. 5290-5305, July 2016.

[30] M. Rivera, V. Yaramasu, A. Llor, J. Rodriguez, B. Wu, and M. Fadel, "Digital predictive current control of a three-phase four-leg inverter," IEEE Transactions on Industrial Electronics, vol. 60, no. 11, pp. 4903-4912, Nov. 2013.

[31] A. G. Yepes, A. Vidal, J. Malvar, O. López, and J. Doval-Gandoy, "Tuning method aimed at optimized settling time and overshoot for synchronous proportional-integral current control in electric machines," IEEE Transactions on Power Electronics, vol. 29, no. 6, pp. 3041-3054, June 2014.

[32] J. Xu, T. Tang, and S. Xie, "Research on low-order current harmonics rejections for grid-connected LCL-filtered inverters," IET Power Electronics, vol. 7, no. 5, pp. 1227-1234, May 2014.

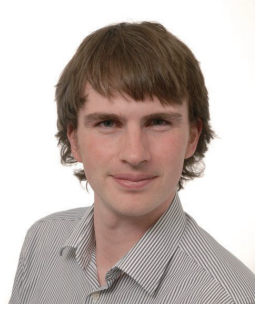

Christoph H. van der Broeck received the B. Sc. and M. Sc. degree in electrical engineering from RWTH Aachen University, Germany, in 2010 and 2013. From 2011 to 2012 he joined the Wisconsin Electric Machine and Power Electronic Consortium at the University of Wisconsin, Madison, as a Fulbright Scholar. Between 2012 and 2013 he worked with AixControl $\mathrm{GmbH}$ on control design of power converters. Since January 2014, he has been working towards the Ph.D. degree at the Institute for Power Electronics and Electrical Drives (ISEA), RWTH Aachen University. His research interests include the modeling and control of power electronic converters and drives.

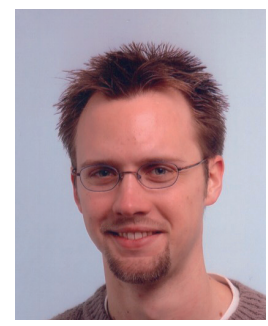

Sebastian A. Richter received the Ph.D. degree in electrical engineering from RWTH Aachen University, Germany, in 2013. Since his time as research associate at the Institute for Power Electronics and Electrical Drives (ISEA), RWTH Aachen University, he manages the group Control \& Simulation at AixControl GmbH, Aachen, Germany. His research interests include control of power electronic converters, renewable energy and power quality.

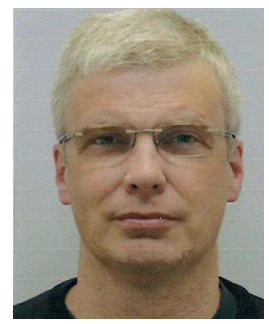

Jochen von Bloh received the Ph.D. degree in electrical engineering from RWTH Aachen University, Germany, in 2001. Until 2002 he led the research group for power electronics as chief engineer at the Institute for Power Electronics and Electrical Drives (ISEA). In 2002 he founded the AixControl GmbH, a company specialized in Rapid Power Prototyping tools, power electronic design and test systems for power electronic application. His research interests include control of power electronic converters, power quality and EMI issues.

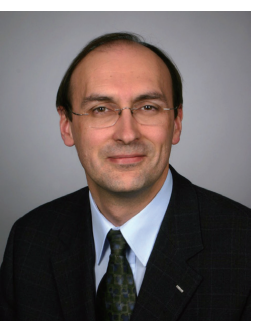

Rik W. De Doncker received the Ph.D. degree in electrical engineering from the Katholieke Universiteit Leuven, Leuven, Belgium, in 1986. In 1987, he was appointed as a Visiting Associate Professor at the University of Wisconsin, Madison. After a short stay as an Adjunct Researcher with Interuniversity Microelectronics Centre, Leuven, he joined, in 1989, the Corporate Research and Development Center, General Electric Company, Schenectady, NY. In 1994, he joined Silicon Power Corporation, a former division of General Electric Inc., as the Vice President of Technology. In 1996, he became a Professor at RWTH Aachen University, Aachen, Germany, where he currently leads the Institute for Power Electronics and Electrical Drives. Since 2006, he has been the Director of the E.ON Energy Research Center, RWTH Aachen University. Dr. De Doncker was the President of the IEEE Power Electronics Society (PELS) in 2005 and 2006. He was the founding Chairman of the German IEEE Industry Applications Society PELS Joint Chapter. In 2002, he was the recipient of the IEEE IAS Outstanding Achievement Award. In 2008, he received the IEEE PES Nari Hingorani Custom Power Award. In 2009, he led a VDE/ETG Task Force on Electric Vehicles. In 2010, he received an honorary doctor degree of TU Riga, Latvia. In 2013, he received the IEEE William E. Newell Power Electronics Award. 